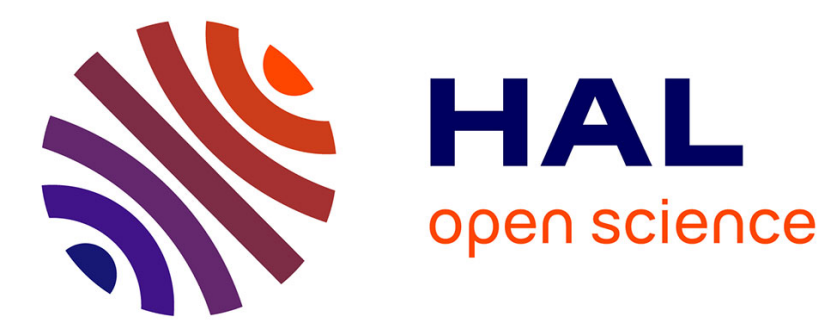

\title{
Towards scalable and accurate molecular dynamics using the SIBFA polarizable force field
}

Louis Lagardère, Léa El-Khoury, Sehr Naseem-Khan, Félix Aviat, Nohad

Gresh, Jean-Philip Piquemal

\section{- To cite this version:}

Louis Lagardère, Léa El-Khoury, Sehr Naseem-Khan, Félix Aviat, Nohad Gresh, et al.. Towards scalable and accurate molecular dynamics using the SIBFA polarizable force field. AIP Conference Proceedings, 2017. hal-01521838

\section{HAL Id: hal-01521838 \\ https://hal.science/hal-01521838}

Submitted on 12 May 2017

HAL is a multi-disciplinary open access archive for the deposit and dissemination of scientific research documents, whether they are published or not. The documents may come from teaching and research institutions in France or abroad, or from public or private research centers.
L'archive ouverte pluridisciplinaire HAL, est destinée au dépôt et à la diffusion de documents scientifiques de niveau recherche, publiés ou non, émanant des établissements d'enseignement et de recherche français ou étrangers, des laboratoires publics ou privés. 


\title{
Towards scalable and accurate molecular dynamics using the SIBFA polarizable force field
}

\author{
Louis Lagardère ${ }^{1}$, Léa El-Khoury ${ }^{1}$, Sehr Naseem-Khan ${ }^{1}$, Félix Aviat ${ }^{1}$, \\ Nohad Gresh ${ }^{1}$, Jean-Philip Piquemal ${ }^{1,2,3 a)}$
}

\author{
${ }^{1}$ UPMC, Sorbonne Universités, Laboratoire de Chimie Théorique, UMR 7616, 75252 Paris Cedex 05, \\ Paris, France; \\ 2 Institut Universitaire de France, 75005 Paris, France; \\ ${ }^{3}$ University of Texas at Austin, Department of Biomedical Engineering, Austin, TX, USA.
}

${ }^{\text {a)} C o r r e s p o n d i n g ~ a u t h o r: ~ j p p @, 1 c t . j u s s i e u . F r ~(J P P) ~}$

\begin{abstract}
We present a short overview of the recent developments and applications of the SIBFA (Sum of Interactions Between Fragments Ab initio computed) polarizable force field.
\end{abstract}

Molecular dynamics (MD) simulations are now an important tool in the chemistry laboratories as they enable the evaluation of macroscopic properties through the use of statistical physics or serve as theoretical microscope to help experimentalists to understand structural properties of biological systems or materials. For a long time, simulations were mainly performed using first generation (i.e. non polarizable) force field models that have the key advantage to enable a fast evaluation of both energies and forces allowing sufficient efficiency to perform million (if not billions) of MD steps. This condition is mandatory to allow sufficient sampling to approach the ergodic hypothesis. For these reasons, community codes such as AMBER [1], CHARMM [2], GROMACS [3] or NAMD [4] appeared and provided large scale capabilities for the-modelers in link with massively parallel simulations on supercomputers and/or on Graphics Processing Unit (GPUs) cards. Until recently, simulation possibilities with more advanced polarizable force fields such as SIBFA (Sum of Interactions Between Fragments Ab initio computed) [5] or AMOEBA [6] were still limited by their inherent speed and scalability. This has very recently changed with the advent of GPU codes such as Tinker-OpenMM [7] and thanks to the availability of a massively parallel interface (MPI) version of Tinker denoted Tinker-HP.[8] These modernization/parallelization efforts combined with new algorithmics have changed the status of polarizable force fields which are not slow anymore. They can now perform long simulations providing enough sampling for free energy computations. In this context, the AMOEBA force field is becoming a popular tool. However, other polarizable force fields will soon become available on the Tinker-HP platform which offers various new algorithmic advances dedicated to polarizable force fields. For example, TinkerHP includes an fast and accurate non-iterative Truncated Conjugated Gradient (TCG) polarization solver [9] offering analytical forces (no MD drifts anymore!) which is available together with more standard iterative methods such as JI/DIIS or Preconditioned Conjugate Gradient (PCG).[10] It also includes an efficient domain decomposition (dd)-Cosmo polarizable continuum method [11] and various polarizable QM/MM possibilities.[12] 
In this context, the SIBFA force field is now available thanks to a final derivation of all its gradients and it will benefit from all these advances. SIBFA is a polarizable force field formulated and calibrated on the basis of ab initio Quantum Chemistry energy decomposition analyses such as SAPT [13] or CSOV. [14] Using distributed multipoles, its purpose is to enable the simultaneous and reliable computations of both intermolecular and conformational energies governing the binding selectivities of biologically and pharmacologically-relevant molecules.

In SIBFA, the intermolecular interaction energy is computed as a sum of five separate contributions [5]:

$$
\Delta \mathrm{E}_{\mathrm{tot}}=\mathrm{E}_{\mathrm{MTP}} *+\mathrm{E}_{\mathrm{rep}}+\mathrm{E}_{\mathrm{pol}}+\mathrm{E}_{\mathrm{ct}}+\mathrm{E}_{\mathrm{disp}}
$$

$\mathrm{E}_{\mathrm{MTP}} *$ is the electrostatic (multipolar) contribution, computed with distributed multipoles derived from the ab initio wave function of the constitutive fragments. It includes a short-range penetration correction. [15] The multipoles (up to quadrupoles) are located on the atoms and bond barycenters. $E_{\text {rep }}$ is the short-range repulsion energy, computed as a sum of bond-bond, bond-lone pair, and lone pair-lone pair interactions. [16] $E_{p o l}$ is the polarization energy contribution, computed with distributed, anisotropic polarizabilities. These are located on the centroids of the localized orbitals, heteroatoms and bond barycenters, and are also derived from ab initio QC computations. $E_{\mathrm{ct}}$ is the charge-transfer energy, in which a coupling with the polarization is introduced, and $\mathrm{E}_{\mathrm{disp}}$ is the dispersion energy contribution.

In recent years, SIBFA has been shown to be a reliable and accurate method enabling a very rich diversity of applications owing to its capability of dealing with charged systems including metal cations. Of course, biological systems are the main target offering complex studies on metalloprotein systems, nucleic acids, or systems interacting with metals.[17] It also enables to tackle systems usually mostly devoted to quantum chemistry studies [18] such as lead compounds [19] or lanthanides and actinides.[20] The availability of SIBFA in a periodic boundary condition context using Smooth Particle Ewald [21] is the key step in the new possibilities offered to the Tinker-HP user. Tinker-HP now allows to perform hundreds of nanosecond simulations on difficult systems including free energy computations such as those presently done by AMOEBA. [22] The work presently undertaken also offers novel perspectives for the Tinker-HP implementation of the third generation Gaussian Electrostatic Model GEM force field which is based on electron density [23]

\section{ACKNOWLEDGMENTS}

This work was supported in part by French state funds managed by CalSimLab and the ANR within the Investissements d'Avenir program under reference ANR-11-IDEX-0004-02. Funding from French CNRS through a PICS grant between UPMC and UT Austin is acknowledged. Jean-Philip Piquemal is grateful for support by the Direction Générale de l'Armement (DGA) Maitrise NRBC of the French Ministry of Defense.

\section{REFERENCES}

1. D.A. Case, D.S. Cerutti, T.E. Cheatham, III, T.A. Darden, R.E. Duke, T.J. Giese, H. Gohlke, A.W. Goetz, D. Greene, N. Homeyer, S. Izadi, A. Kovalenko, T.S. Lee, S. LeGrand, P. Li, C. Lin, J. Liu, T. Luchko, R. Luo, D. Mermelstein, K.M. Merz, G. Monard, H. Nguyen, I. Omelyan, A. Onufriev, F. Pan, R. Qi, D.R. Roe, A. Roitberg, C. Sagui, C.L. Simmerling, W.M. Botello-Smith, J. Swails, R.C. Walker, J. Wang, R.M. Wolf, X. Wu, L. Xiao, D.M. York and P.A. Kollman (2017), AMBER 2017, University of California, San Francisco.

2. B.R. Brooks, C.L. Brooks, III, A.D. MacKerell, Jr., L. Nilsson, R.J. Petrella, B. Roux, Y. Won, G. Archontis, C. Bartels, S. Boresch, A. Caflisch, L. Caves, Q. Cui, A.R. Dinner, M. Feig, S. Fischer, J. Gao, M. Hodoscek, W. Im, K. Kuczera, T. Lazaridis, J. Ma, V. Ovchinnikov, E. Paci, R.W. Pastor, C.B. Post, J.Z. Pu, M. Schaefer, B. Tidor, R. M. Venable, H. L. Woodcock, X. Wu, W. Yang, D.M. York, and M. Karplus, J Comput Chem. 30, 1545-1614 (2009).

3. H. J. C. Berendsen. D. van der Spoel, R. van Drunen, Comp. Phys. Comm. 91, 43-56 (1995) 
4. J. C. Phillips, R. Braun, W. Wang, J. Gumbart, E.Tajkhorshid, E. Villa, C. Chipot, R. D. Skeel, L. Kalé, K. Schulten, J. Comput. Chem 26, 1781-1802 (2005)

5. N. Gresh, G. A. Cisneros, T. A. Darden and J-P Piquemal, J. Chem. Theory. Comput., 3, 1960-1986 (2007)

6. P. Ren and J. W. Ponder, J. Phys. Chem. B, 107, 5933-5947 (2003)

7. M. Harger, D. Li, Z. Wang, K. Dalby, L. Lagardère, J.-P. Piquemal, J. Ponder, P. Ren, J. Comput. Chem., in press (2017)

8. http://www.i2ct.upmc.fr/tinkerHP

9. F. Aviat, A. Levitt, Y. Maday, B. Stamm, P. Y. Ren, J. W. Ponder, L. Lagardere, J.-P.Piquemal, J. Chem. Theory. Comput., 13, 180-190 (2017)

10. a) F. Lipparini, L. Lagardere, B. Stamm, E. Cances, M. Schnieders, P. Y. Ren, Y. Maday and J.-P. Piquemal, J. Chem. Theory. Comput., 10, 1638-1651 (2014); b) L. Lagardere, F. Lipparini, E. Polack, B. Stamm, E. Cances, M. Schnieders, P. Y. Ren, Y. Maday and J.-P. Piquemal, J.Chem. Theory. Comput., 11, 2589-2599 (2015)

11. F. Lipparini, L. Lagardere, C. Raynaud, B. Stamm, E. Cances, M. Schnieders, P. Y. Ren, B. Mennucci, Y. Maday and J.-P. Piquemal, J. Chem. Theory. Comput., 11, 623-634 (2015)

12. a)E. G. Kratz, A. R. Walker, L. Lagardere, F. Lipparini, J.-P. Piquemal and G. A. Cisneros, J. Comput. Chem., 37, 1019-1029 (2016); b) D.Loco, E. Polack, S. Caprasecca, L. Lagardere, F. Lipparini, J.-P. Piquemal and B. Mennucci, J. Chem. Theory. Comput., 12, 3654-3661 (2016)

13. B. Jeziorski, R. Moszyński, and K. Szalewicz, Chem. Rev. 94, 1887 (1994).

14. J-P. Piquemal, A. Marquez, O. Parisel and C. Giessner-Prettre, J. Comput. Chem. 26, 1052-1062 (2005)

15. J-P. Piquemal, N. Gresh and C. Giessner-Prettre, J. Phys. Chem A 107, 10353-10359 (2003)

16. a)J-P Piquemal, H. Chevreau and N. Gresh, J. Chem. Theory. Comput. 3, 824-837 (2007); b) R. Chaudret, N. Gresh, O. Parisel, J-P. Piquemal, J. Comput. Chem. 32, 2949-2957 (2011); c) L. El-Khoury, S. NaseemKhan, K. Kwapien, D. Perahia, Z. Hobaika, R. Maroun, J.-P. Piquemal, N. Gresh, J. Comput. Chem., in press (2017), DOI: $10.1002 /$ jcc. 24830

17. a) N. Gresh, J. E. Sponer, M. Devereux, B. de Courcy, J-P. Piquemal, J. Sponer, J. Phys. Chem. B, 119, 9477-9495 (2015); b) N. Gresh, K. El Hage, D. Perahia, J-P. Piquemal, C.Berthomieu, D. Berthomieu.,J. Comput. Chem., 35, 2096-2106 (2014); c) K. El Hage, J.-P. Piquemal, Z. Hobaika, R. G. Maroun, N. Gresh, J. Phys. Chem. A 118, $9772-9782$ (2014); d) M. Devereux, N. Gresh, J.-P. Piquemal and M. Meuwly, J. Comput. Chem. 35, 1577-1591 (2014); e) N. Gresh, D. Perahia, B. de Courcy, J. Foret, C. Roux, L. El-Khoury, J-P. Piquemal, L. Salmon, J. Comput. Chem., 37, 2770-2782 (2016) ; f) N. Gresh, S. Naseem-Khan, L. Lagardère, J.-P. Piquemal, J. E. Sponer, J. Sponer, J. Phys. Chem. B, 121, 3997-4014 (2017).

18. a)C. Gourlaouen, H. Gérard, J.-P. Piquemal and O. Parisel, 2008, Chem. Eur. Journ. 14, 2730-2743 (2008); b) C. Gourlaouen, J-P. Piquemal, T. Saue and O. Parisel, J. Comput. Chem. 27, 142-156 (2006)

19. M. Devereux, M.-C. van Severen, O. Parisel, J-P Piquemal andN. Gresh, J. Chem. Theo. Comput. 7, 138$147(2011)$

20. A. Marjolin, C. Gourlaouen, C. Clavaguera, N. Gresh, P. Y. Ren, J. Wu, J.-P. Dognon and J.-P. Piquemal, Theo. Chem. Acc., 131, 1198 (2012)

21. C. Narth, L. Lagardere, E. Polack, N. Gresh, Q. Wang, D. R. Bell, J. Rackers, J. Ponder, P. Ren and JeanPhilip Piquemal, J. Comput. Chem., 37, 494-506 (2016)

22. J. Zhang, W. Yang, J.-P. Piquemal and P. Ren, J. Chem. Theo. Comput., 18, 1314-1324 (2012)

23. J-P. Piquemal, G. A. Cisneros, P. Reinhardt, N. Gresh and T. A. Darden, J. Chem. Phys. 124, 104101(2006); b) G. A. Cisneros, J-P. Piquemal and T. A. Darden, J. Phys. Chem. B. 110, 13682-13684 (2006); c) G. A. Cisneros, J-P. Piquemal and T. A. Darden, J. Chem. Phys. 125, 184101 (2006); d) R. Duke, O. Starovoytov, J.-P. Piquemal, and G. A. Cisneros, J. Chem. Theory Comput. 10, 1361-1365 (2014) 